\title{
Peran Manajemen Public Relations NoonaKu Signature dalam Membangun Reputasi
}

\author{
Reggiana, H. H. Daniel Tamburian \\ Reggianaguntur02@gmail.com,danielt@fikom.untar.ac.id \\ Fakultas Ilmu Komunikasi Universitas Tarumanagara
}

\begin{abstract}
Noonaku Signature is one of the cheap clothing producers who managed to be a limited liability company $(P T)$. By selling clothing at a cheap price, Noonaku strives to build its reputation in order to reach all circles. Every company should have a good public relations $(P R)$ to get a good reputation. The research was conducted to find out the role of $P R$ management NoonaKu Signature in building a reputation. The role of this PR management can be seen from programs or activities conducted by Noonaku. Using the theory of the role of $P R$ according Dozier \& Broom, there are four $P R$ roles that are expert advisors, communication facilitators, problem solving process facilitators, and communication technicians. Then the theory according to Scott \& Cutlip There are four strategies that can be used by public relations to build the company's reputation: fact finding, planning, communication, and evaluation. The study used a qualitative approach with in-depth interview techniques on three informant individuals. The collection of data on this research is done by doing observations to see directly the program that is being run by the PR NoonaKu. In addition, there is a photo documentation of the social media NoonaKu. The results of the research in PT. NoonaKu design Indonesia shows the role of PR management in NoonaKu is very well done to build its reputation in the community through its programs that suits the vision, mission, and value of NoonaKu.
\end{abstract}

Keywords: management of public relations, strategy, reputation

\begin{abstract}
Abstrak
Noonaku Signature merupakan salah satu produsen pakaian murah yang berhasil menjadi perseroan terbatas (PT). Dengan menjual pakaian dengan harga yang murah, Noonaku berusaha membangun reputasinya agar dapat menjangkau semua kalangan. Setiap perusahaan harus memiliki public relations (PR) yang baik untuk mendapatkan reputasi yang baik. Penelitian ini dilakukan untuk mengetahui peran manajemen PR NoonaKu Signature dalam membangun reputasi. Peran manajemen PR ini dapat kita lihat dari program-program atau kegiatan-kegiatan yang dilakukan oleh Noonaku. Menggunakan teori peranan PR menurut Dozier \& Broom, terdapat empat peranan $P R$ yaitu penasehat ahli, fasilitator komunikasi, fasilitator proses pemecahan masalah, dan teknisi komunikasi. Kemudian teori menurut Scott \& Cutlip terdapat empat strategi yang dapat digunakan oleh public relations untuk membangun reputasi perusahaannya yaitu fact finding, planning, communication, dan evaluation. Penelitian ini menggunakan pendekatan kualitatif dengan teknik wawancara mendalam pada tiga orang informan. Pengumpulan data pada penelitian ini dilakukan dengan melakukan observasi untuk melihat langsung program yang sedang dijalankan oleh PR NoonaKu. Selain itu juga ada dokumentasi berupa foto tampilan dari sosial media NoonaKu. Hasil penelitian di PT. NoonaKu Desain Indonesia ini menunjukkan peran manajemen PR di NoonaKu dilakukan dengan sangat baik untuk membangun reputasinya di masyarakat melalui program-programnya yang sesuai dengan visi, misi, dan value dari NoonaKu.
\end{abstract}

Kata Kunci: manajemen PR, strategi, reputasi. 


\section{Pendahuluan}

Saat ini pakaian tidak hanya sebagai penutup aurat tetapi menjadi gaya hidup untuk menaikkan status sosial atau popularitas. Dengan beragam trend terbaru yang selalu mengalami perubahan, masyarakat Indonesia berlomba menunjukkan dirinya melalui gaya berbusana. Hal ini dikarenakan adanya pengaruh gaya berbusana Barat yang masuk ke Indonesia.

Salah satu bidang yang paling berkembang di Indonesia adalah industri clothing line. Clothing line merupakan bisnis yang bergerak dalam bidang fashion, dimana mereka memproduksi sendiri barang yang mereka jual dan membuat brand mereka sendiri. Bisnis ini dapat berkembang karena trend berpakaian masa kini yang selalu berubah.

Berbagai brand busana wanita kini banyak kita jumpai. Dengan beragam model dirancang untuk dapat menjadi tren yang banyak diminati kaum hawa. Tidak perlu membuka di Mall, saat ini brand clothing dapat berjualan atau memasarkan produknya hanya dengan melalui media sosial.

Agar menjadi brand yang unggul dalam berbisnis, harus dapat menarik minat dan kepercayaan masyarakat. Terutama pada perusahaan barang saat memulai bisnis, reputasi yang baik menjadi hal yang sangat penting. Penerimaan dan tanggapan publik yang positif merupakan hubungan yang harmonis antara perusahaan dengan publik.

Penelitian terdahulu yang dilakukan oleh Ferlita Lorensia (2018) mengenai strategi public relations PT. Kereta Commuter Indonesia dalam memulihkan reputasinya mengelola krisis yang terjadi yaitu perubahan sistem E-ticketing. Penelitian ini menggunakan teknik pengumpulan data yaitu teknik observasi terus terang atau samar - samar, teknik wawancara dan tehnik dokumentasi. Tujuan dari penelitian ini adalah untuk mengetahui bagaimana strategi yang dilakukan oleh public relations dalam memulihkan reputasi perusahaannya pasca terjadinya krisis perubahan sistem E-ticketing yang berdampak pada terganggunya proses masuk dan keluar penumpang di setiap stasiun.

Berikut adalah teori maupun penjelasan yang digunakan pada penelitian ini yaitu komunikasi merupakan kegiatan yang tidak pernah lepas dari kehidupan manusia. Menurut Kamus Besar Bahasa Indonesia, komunikasi adalah pengiriman dan penerimaan pesan atau berita antara dua orang atau lebih sehingga pesan yang dimaksud dapat dipahami. Komunikasi yang dilakukan oleh perusahaan kepada masyarakat adalah melalui seorang praktisi public relations.

Public relations (PR) adalah fungsi yang membangun dan mempertahankan hubungan yang baik dan bermanfaat antara organisasi dengan publik yang memengaruhi kesuksesan atau kegagalan organisasi tersebut. Sehingga peran PR sangatlah penting bagi perusahaannya dalam membangun reputasinya. Aktivitas Public Relations adalah mengelola komunikasi antara organisasi dan publiknya. Sementara itu, praktik PR adalah memikirkan, merencanakan dan mencurahkan daya untuk membangun dan menjaga saling pengertian antara organisasi dan publiknya.

Untuk membangun reputasi perusahaannya, dibutuhkan pengelolaan strategi dari PR perusahaan tersebut. Strategi adalah bagian terpadu dari suatu rencana, sedangkan rencana merupakan produk dari suatu perencanaan, yang pada akhirnya perencanaan adalah salah satu fungsi dasar dari proses manajemen (Ruslan 2012). 
Sehingga dapat ditarik kesimpulan bahwa peran manajemen PR suatu perusahaan adalah mengatur strategi bagi perusahaannya.

NoonaKu Signature menjual produknya dengan harga yang murah yaitu dibawah seratus ribu rupiah. Namun NoonaKu dapat menjamin bahwa selain kualitas bahan yang baik, NoonaKu juga memberikan pelayanan yang baik sehingga membeli produknya yang murah tapi tidak murahan. Hal ini yang membuat peran PR sangat dibutuhkan. Salah satu peran dari manajemen PR NoonaKu Signature adalah menyusun strategi dengan membuat program-program yang akan dijalankan untuk membangun reputasi NoonaKu di mata masyarakat.

\section{Metode Penelitian}

Penelitian kualitatif adalah pengumpulan data pada suatu latar alamiah, dengan menggunakan metode alamiah, dan dilakukan oleh orang atau peneliti yang tertarik secara alamiah (Moelong 2009). Penelitian kualitatif berusaha menggali dan memahami pemaknaan akan kebenaran yang berbeda-beda oleh orang yang berbeda. Pemilihan metode penelitian akan menentukan tehnik dan alat pengumpilan data yang digunakan. Penelitian kualitatif yang dilakukan oleh adalah kualitatif deksriptif. Berdasarkan metode yang digunakan, akan menjelaskan mengenai peran PR NoonaKu Signature dalam membangun reputasi perusahaannya melalui wawancara yang dilakukan. Subjek dalam penelitian ini adalah Florentia Jeanne sebagai PR dari NoonaKu. Objek penelitian dalam penelitian ini adalah berkaitan dengan program yang dibuat oleh PR NoonaKu dalam membangun reputasi perusahaannya. Metode pengumpulan data yang dilakukan adalah dengan melakukan wawancara secara mendalam dengan tiga informan yaitu dari para pelanggan setia NoonaKu dan PR dari NoonaKu Signature

\section{Hasil Penemuan dan Diskusi}

\section{a. Manajemen Public Relations (PR) Noonaku Signature}

Peran PR Noonaku Signature sangatlah penting dalam membangun reputasi perusahaannya. Menjual pakaian dengan harga murah yaitu dibawah seratus ribu rupiah, PR Noonaku bertugas untuk menyampaikan kepada masyarakat bahwa kualitas yang diberikannya tidaklah murahan. Peran atau tugas dari seorang PR adalah mempublikasikan kepada khalayak tentang gambaran perusahaannya untuk membangun reputasi. PR NoonaKu telah melakukan tugasnya dengan baik melalui program-program atau strategi yang dijalankan dalam membangun reputasi perusahaannya.

\section{b. Pengelolaan Program PR}

Dalam melakukan atau menjalankan program-program PR NoonaKu Signature memanfaatkan beberapa media sosial yang banyak diminati atau dilihat oleh para kaum milenial wanita. Media sosial ini digunakan untuk memasarkan produk maupun memberikan informasi tentang NoonaKu Signature sehingga dapat meningkatkan brand awareness tentang NoonaKu. Media sosial yang digunakan oleh NoonaKu Signature adalah Instagram dan Youtube. Setiap harinya, NoonaKu akan mengunggah foto dan video pada media sosialnya 
tersebut untuk memberikan informasi mengenai produk-produknya serta aktivitas atau kegiatan yang sedang dilakukan oleh NoonaKu misalnya seperti bazaar serta menjadi pembicara pada suatu kegiatan.

\section{c. Strategi Public Relations (PR) NoonaKu Signature}

Melalui program-program yang dibuat oleh NoonaKu, strategi yang digunakan adalah dengan menyampaikan kepada masyarakat bahwa meskipun dengan harga yang murah pembeli tidak hanya membeli pakaian tapi juga integritas dan kenyamanan sehingga pembeli akan cepat untuk kembali membeli. Hal ini yang membuat NoonaKu Signature dapat terus mmempertahankan para pelanggannya dan menambah para pembelinya dari berbagai kalangan.

Strategi yang dilakukan oleh manajemen PR Noonaku

Manajemen PR NoonaKu membuat program-program untuk membangun reputasi perusahaannya. Hal utama yang perlu dilakukan adalah dengan membangun kepercayaan masyarakat terhadap kualitas produk serta pelayanan NoonaKu. Dengan begitu para masyarakat dapat menjadi pelanggan setia NoonaKu serta dapat menjadi PR dari NoonaKu kepada teman-temannya. NoonaKu Signature mampu menjadikan dirinya sebagai perseroan terbatas (PT) melalui program yang dibuatnya selama ini untuk mempertahankan pelanggannya. Dimulai dengan mempelajari permasalahan atau fenomena yang terjadi pada masyarakat bahwa online shop saat itu banyak yang menjual pakaian namun barang yang diterima tidak sesuai dengan difoto baik dari segi bahan maupun pola. NoonaKu membuat strategi dengan memberikan foto model dengan pakaian yang asli dan nyata dengan menggunakan kualitas gambar yang bagus.

Kemudian dalam hal pelayanan, NoonaKu mampu memberikan kenyamanan yang mahal untuk membuktikan kepada masyarakat bahwa di NoonaKu belanja murah tapi tidak murahan. Pada online store, Noonaku memberikan pelayanan respon yang cepat saat pembeli atau masyrakat bertanya melalui aplikasi Line ataupun web NoonaKu. Hal ini dikarenakan NoonaKu mempelajari fenomena atau permasalahan yang terjadi saat ini adalah para online shop lainnya kerap kali memberikan respon yang lama dan tidak informatif sehingga masyrakat menjadi kurang nyaman dan berpindah ke toko lainnya untuk mendapatkan pelayanan yang lebih baik agar produk juga dapat sampai kepada pembeli dengan cepat. Sedangkan pada offline boutique, NoonaKu memberikan kenyamanan kepada para pengunjungnya saat berada di butik. Hal ini dilakukan dengan memberikan desain butik yang terlihat bersih dan bagus seperti di butik mal atau butik yang menjual produknya dengan mahal, sehingga para pengunjung nyaman saat berada di dalam butik dan ingin mencoba semua produk yang dijual oleh NoonaKu.

Dalam melakukan atau menjalankan program-program PR NoonaKu Signature memanfaatkan beberapa media sosial yang banyak diminati atau dilihat oleh para kaum milenial wanita. Media sosial ini digunakan untuk memasarkan produk maupun memberikan informasi tentang NoonaKu Signature sehingga dapat meningkatkan brand awareness tentang NoonaKu. Program atau kegiatan NoonaKu untuk campaign sosial media, enggaged yang paling tinggi adalah Instagram dan Youtube. Dalam membuat suatu pemberitahuan mengenai program ataupun produk yang ingin disampaikan, Noonaku tidak hanya melalui 
foto tetapi juga membuat video. Hal ini dilakukan sebagai permasalahan yang terjadi saat ini, bahwa masyrakat akan lebu mudah dan tertarik untuk melihat dan mendengar video dibandingkan membaca caption yang panjang. Foto dan video yang diunggah oleh NoonaKu bukanlah yang hanya menggunakan kamera kualits rendah dan diedit dengan aplikasi yang standar, melainkan NoonaKu memiliki photographer serta videographernya sendiri sehingga foto dan video yang dihasilkan memiliki kualitas yang baik.

Pemanfaatan media sosial sangatlah penting sebagai media promosi guna membangun reputasi perusahaan. Pada zaman yang sudah canggih saat ini, media sosial memiliki dampak atau efek yang sangat besar dibandingkan dengan media-media konvensional lainnya seperti media cetak, radio, dan televisi. Namun sebelum mengunggah suatu foto atau video di media sosialnya, PR diperlukan pengelolaan yang baik agar dapat sesuai dengan sasaran yang ingin dicapai yaitu dengan cara memperlihatkan kepada mereka yang kira-kira seperti target dari NoonaKu, bagaimana tanggapannya saat melihat foto atau video tersebut. Apakah pesan atau makna yang ingin disampaikan oleh NoonaKu dapat sesuai dengan tujuan NoonaKu kepada target sasaran. Setelah foto atau video sudah siap untuk diunggah, pada saat akan mengunggah NoonaKu memili strategi khusus yaitu dengan memperhatikan waktu yang tepat serta konten yang disajikan dalam sebuah video harus dapat menarik perhatian para masyarakatnya agar sesuai dengan target dari program yang dibuat

\section{Simpulan}

NoonaKu Signature menjual produknya dengan harga yang murah, meskipun demikian, NoonaKu memberikan kualitas yang tidak murahan. Hal ini dibuktikan dengan NoonaKu mampu menjadikan dirinya sebagai perseroan terbatas (PT). Dengan peran manajemen PR NoonaKu, mereka terus berusaha membuat dan menjalankan program-program untuk dapat membangun reputasinya di masyrakat.

\section{Ucapan Terima Kasih}

Penulis mengucapkan terima kasih kepada pihak-pihak yang telah membantu dalam proses penelitian hingga dipublikasikan, terutama kepada narasumber yang telah bersedia meluangkan waktu untuk kerjasamanya selama proses penelitian ini berlangsung.

\section{Daftar Pustaka}

Moleong, Lexy J. 2009. Metodologi Penelitian Kualitatif. Bandung: Remaja Rosdakarya.

Ruslan, Rosady. 2012.Manajemen Public Relations dan Media Komunikasi. Jakarta: PT. Raja Grafindo Persada.

Ferlita Lorensia. 2018. Peran Public Relations dalam Memulihkan Reputasi (Studi Kasus Manajemen Krisis di PT. Kereta Commuter Indonesia pasca petrubahan sistem e-ticketing). Skripsi Komunikasi Universitas Tarumanagara. 